\title{
LABORATORY SCREENING OF SOME SAPROPHYTIC COFFEE SURFACE MICROFLORA ANTAGONISTIC TO Colletotrichum kahawae
}

\author{
ELIJAHKGICHURU \\ Coffee Research Foundation \\ P O Box 4 RUIRU, Kenya \\ Email: ekgichuru@yahoo.com
}

\begin{abstract}
Saprophytic microflora were isolated from coffee berry surfaces. Eight isolates were selected for antagonistic tests against Colletotrichum kahawae. Six isolates (Bacillus macerans [two isolates], Epicoccum nigrum, Aspergillus niger, Penicillium citrinum and Pestalotiopsis $s p$ ) were selected for having inhibition zones against fungi on isolation plates and two isolates (Cladosporium sp. and Phoma sp.) were selected as being most common and populous. All the antagonists reduced germination of Colletotrichum kahawae on detached green coffee berries and with exception of Pestalotiopsis $s p$. they reduced appresoria formation. They all reduced infection of the berries and sporulation of Colletotrichum $s p$. on detached maturing coffee twigs. Four of the antagonists (Bacillus macerans, Epicoccum nigrum, Aspergillus niger and Cladosporium $s p$.) were found to reduce infection when used in mixtures and when grown on whole maize meal broth. It was concluded that there is potential of using saprophytic coffee surface microflora in biological control of coffee berry disease. It would also be possible to develop farm-based technology to use the microflora. Future research needs in this area are presented.
\end{abstract}

Key words: Colletotrichum kahawae, microflora, antagonists, coffee berry disease

\section{RESUME}

CRIBLAGE EN LABORATOIRE DE QUELQUES MICROFLORES SAPROPHYTES DE CAFEIER ANTAGONISTES AU Colletotrichum kahawae

\begin{abstract}
La microflore saprophyte de surface a été isolée des baies de café. Huit isolats ont été sélectionnés pour les tests d'antagonisme contre Colletotrichum kahawae. Six isolats (Bacillus macerans [deux isolats], Epicoccum nigrum, Aspergillus niger, Penicillium citrinum et Pestalotiopsis $\mathrm{sp}$ ) ont été sélectionnés pour avoir présenté des zones d'inhibition contre le champignon en milieu artificiel et les deux autres (Cladosporium $\mathrm{sp}$. et Phoma sp.) en raison de leur présence habituelle en conditions naturelles. Tous les antagonistes ont réduit la germination de Colletotrichum kahawae sur les baies vertes détachées de café et ils ont, à l'exception de Pestalotiopsis sp., permis de réduire la formation appressoriale. Ils ont tous permis de réduire l'infection des baies et la sporulation de Colletotrichum sp. sur les jeunes rameaux détachés. Quatre des ces antagonistes (Bacillus macerans, Epicoccum nigrum, Aspergillus niger et Cladosporium sp.) ont réduit l'infection lorsqu'ils sont utilisés en mélange et cultivés dans un milieu de culture à base de farine de maïs. Il a été conclut qu'il existe un potentiel pour le contrôle biologique de l'anthracnose des baies de café par l'usage de la microflore saprophyte de surface. II serait ainsi possible de développer des techniques paysannes pour la production de la microflore saprophyte. Les besoins de recherche dans ce domaine seront ci-dessus discutés.
\end{abstract}

Key words: Colletotrichum kahawae, microflore, antagonistes, coffee berry disease 


\section{INTRODUCTION}

Colletotrichum kahawae is the causal agent of coffee berry disease (CBD), first reported in Kenya in 1922 (McDonald 1926). Colletotrichum kahawae is a member of the fungi imperfecti whose sexual stage has not been discovered and reproduction is by conidia produced in pink mucilaginous masses. It infects coffee flowers and the fruits especially in the soft expanding stages causing dark sunken lesion that can coalesce and the whole fruit blackens and dries. Infected berries dry on the tree without maturing or fall down. Losses caused by this disease can be over $80 \%$ if no control is done and conditions are favourable for disease epidemic. Most favourable weather conditions are cool (about $18^{\circ} \mathrm{C}$ ) accompanied by high humidity. It is currently a major limitation to economic production of Coffea arabica in Africa (Masaba and Waller, 1992). Currently, the main control method of the disease is by intensive fungicide spray program (Griffiths et al., 1971) which is costly and largely unaffordable by small-scale coffee farmers, and is environmentally unfriendly. Other effects of fungicide use in coffee include yield increases by 'tonic' effect (Rayner, 1957 ; Mulinge and Griffiths, 1974) and increase of diseases especially if the sprays are mistimed or inadequate (Mulinge and Griffiths, 1974 ; Van der Vossen, 1982 ; Masaba, 1987, 1991). Farms that have never been sprayed with fungicides have low CBD incidence (Furtado, 1969 ; Griffiths, 1972, Gibbs, 1972). Use of the CBD and leaf rust resistant cultivar Ruiru 11 is on the increase but its mass adoption is hampered by low production of the hybrid seed and seedlings (vegetative propagation) (Masaba and Waller, 1992). Moreover, a large proportion of the variety is planted as new establishment rather than replacement of the traditional susceptible varieties. The longevity of the resistance is also not known. There is therefore a need to develop alternative CBD control methods that can supplement or substitute the above in integrated strategies.

Biological control of $\mathrm{CBD}$ provides an alternative to the above problems. The low incidence of CBD in farms not sprayed with fungicides might be due to microbial interactions since such farms have less proportions of $C$. kahawae spores and higher proportion of inactive (scab) lesions, which support a wide spectrum of microflora (Furtado, 1969, 1970 ; Griffiths et al., 1971; Masaba, 1991). Masaba (1991) aimed at establishing the role of saprophytic microflora in the development of CBD in the field and concluded that there is potential of using the microflora to manage the disease in integration with other control measures. The work of Masaba (1991) also demonstrated antagonism of some of the isolated microflora to the CBD pathogen. Pedro (1996) also demonstrated control of the fungus by Bacillus subtilis under laboratory conditions. Biological control of plant pathogens is fundamentally a matter of ecological management of a community of organisms (Van Driesche and Bellow, 1996). There are usually diverse sets of microbes already associated with plant pathogens, which interact negatively with the pathogens. The mechanisms include competition for occupancy of inoculation sites, competition for limited nutrients, antibiotic production, parasitism and induction of resistance. These interactions provide an opportunity for manipulation of resident microflora to achieve reduced pathogen activity hence disease. Resident microbes antagonistic to plant pathogens should be more preferable for biocontrol than those from other habitats (Blakeman and Fokkema, 1982).

The work reported in this paper continues with the objective of collecting and screening local coffee surface microflora for their potential to control $\mathrm{CBD}$ as a prerequisite to field evaluations.

\section{MATERIALS AND METHODS}

Coffee berries both diseased and healthy were randomly picked from coffee growing at Coffee Research Station, Kenya (1608 meters above sea level) and microflora isolated from their surfaces by berry wash method (Masaba, 1991). The washate obtained by vigorous hand shaking of fifty berries in $25 \mathrm{ml}$ sterile distilled water was serially diluted to $10^{-3}$ and $0.1 \mathrm{ml}$ of each dilution plated in triplicate onto Malt Extract Agar (Oxoid) with $0.02 \%$ Streptomycin Sulphate and onto NutrientAgar. The plates were incubated at room temperature $\left(20-26^{\circ} \mathrm{C}\right)$ and observed daily after the fourth day for cultural characteristics of resultant microbial colonies. Microflora with inhibition zones between them were isolated and tested for in vitro antagonism to $C$. kahawae by dual culture test on Potato Dextrose Agar (PDA) (Oxoid). Six isolates exhibiting such antagonism and two of the most populous fungi were chosen for further laboratory tests and sent to $\mathrm{CABI}$ Bioscience for identification. 
All the microflora isolated widespread saprophytes though they could have negative aspects. Members of genus Bacillus are gram negative and produce endospores that help them withstand environmental stress and they generally produce antibiotics. Bacillus macerans has strains that fix nitrogen under stress. The genera Epicoccum, Cladosporiun, Penicillium, Phoma, Aspergillus and Pestalotiopsis are Hypohomycetes of widespread occurrence in nature. They generally are saprophytes though in some conditions they can infect plant (Pestalotiopsis causes leaf spots) or animals to cause mycosis. Aspergillus and Penicillium genera are also considered mycotoxin producers but this is dependent on species and strains. Aspergillus niger has strains that produce the mycotoxin Ochratoxin A (OTA) even in coffee (Duris, 2002).

The antagonists were multiplied on PDA in 9-cm diameter Petri-dishes and incubated at room temperature for ten days. Each isolate was harvested by flooding each Petri-dish with $5 \mathrm{ml}$ sterile distilled water and scraping the surface with sterile blade. The washate was filtered through a single layer of muslin cloth and adjusted using haemocytometer to concentrations shown in Table 1. The concentrations reflect easily available ones after the growth and harvesting procedure. $C$. kahawae used in the experiments was a freshly collected field population at the Coffee Research Station. Each isolate suspension was mixed with the equal volume of $C$. kahawae spore suspension $\left(2 \times 10^{6}\right.$ spores $\left./ \mathrm{ml}\right)$, a drop of the mixture was placed onto detached green coffee berries (variety SL28) and incubated in moist chambers holding 30 berries each at room temperature for 48 hours. Clear nail vanish was applied onto the inoculated spot and peeled off when dry. The vanish peel was mounted in trypan blue in lactophenol and observed under a microscope (x 200). Three microscopic fields per berry and five berries per replicate were observed and the percentage of germinated spores and appresoria formed (based on germinated spores) calculated. The remaining 25 berries per box were left intact and infection records (percentage) taken after 14 days. The whole experiment was repeated twice. $C$. kahawae inoculum used as control was diluted to half strength with sterile distilled water. Four of the antagonists were randomly selected for further experiments. The effects of mixtures of the antagonists on infection of green coffee berries in the laboratory were tested. The standardized microbial suspensions were mixed in equal volumes to constitute test mixtures (Table 2) and these were mixed in equal proportions to $C$. kahawae inoculum and used to inoculate detached green coffee berries as in the procedure above. The four antagonists were also tested for effects on sporulation of Colletotrichum species on detached maturing coffee twigs by the method of Masaba (1986) and sporulation index (SI) calculated using the formula :

\section{SI = Spore count $/ L V$}

Where spore count - Total number of spores in haemocytometer

\section{$\mathrm{L}$ - Total length of twigs per sample in $\mathrm{cm}$ \\ $\mathrm{V}$ - Total volume of twigs per sample in $\mathrm{cm}^{3}$}

The four isolates were grown in whole maize meal broth made in a kitchen pot by boiling while stirring the flour in water in a ratio of about 1 to 6 . The thick broth was kept boiling for 20 minutes and then left to cool to about $50-60^{\circ} \mathrm{C}$. It was then put into three-liter capacity plastic jericans freshly rinsed with boiling water. The jericans were filled to about one sixth of their volume. The preparation was then left to cool to about room temperature while loosely capped. Each jerican was inoculated with one isolate grown for ten days on PDA by cutting the Agar in one Petri-dish into small blocks and dropping them into the jericans. The broths were then shaken thoroughly to mix the inoculum and spread them over the jericans' inner surface. The preparations were then incubated for fourteen days at room temperature opening them daily for about one minute and shaking them on skipa-day routine. After incubation, the height of the broth was marked and raised to four times by adding tap water and shaken thoroughly to mix. The diluted preparation was strained through one layer of muslin cloth and the filtrate used without standardization of spore concentration to test their effect on the infection of detached green coffee berries by $C$. kahawae. A mixture of the four antagonists was also tested. The experimental layout was as described before. 


\section{RESULTS}

All the tested microflora significantly $(P=0.05)$ inhibited the germination percentage of $C$. kahawae conidia on detached green coffee berries (Table 1). The magnitudes of the effects were different for different isolates and even the two isolates of $B$. macerans were significantly different $(P=0.05)$ but they were both inhibitive. All the microflora except Pestalotiopsis sp. which had stimulatory effect, inhibited appresoria formation by C. kahawae. Some conidia were observed to have more than one appresorium while some appresoria could not be traced to their parent conidia. The microflora also significantly $(P=0.05)$ reduced the infection percentage on detached green coffee berries recorded on the $14^{\text {th }}$ day after inoculation.
Mixtures of the four selected microflora significantly $(P=0.05)$ reduced infection of detached green coffee berries by the pathogen (Table 2) though the magnitudes differed. The microflora also reduced sporulation of Colletotrichum $s p$. on maturing bark of coffee twigs and their effects were not significantly $(P=0.05)$ different from that of Copper Nordox (50\% WP) (Table 3). When the four microflora were grown on whole maize meal broth, they significantly $(P=0.05)$ reduced infection of green coffee berries on the fourteenth day after inoculation except $E$. nigrum which was not significantly different from the C. kahawae control (Table 3 ). The highest reduction $(66 \%)$ was by the mixture of all antagonists.

Table 1 : Effects of various microflora on germination and appresoria formation by $C$. kahawae on detached green coffee berries and infection of the berries by the pathogen

Effet de la microflore sur la germination et la formation des appressoria de C. kahawae sur les baies vertes détachées de café et sur l'infection des baies par l'agent pathogène.

\begin{tabular}{lccccc}
\hline Microoganisms & Code $\mathrm{N}^{\text {. }}$ & $\begin{array}{c}\text { Spores/Cells } \\
\text { (per ml) }\end{array}$ & $\begin{array}{c}\text { Inhibition (\%) of C. } \\
\text { kahawae germination }\end{array}$ & $\begin{array}{c}\text { Inhibition (\%) of C. Kahawae } \\
\text { appresoria formation }\end{array}$ & $\begin{array}{c}\text { \% infected } \\
\text { berries }\end{array}$ \\
\hline Bacilus macerans & 1 & $1 \times 10^{9}$ & $73.25 \mathrm{~B}$ & $1161 \mathrm{C}$ & $22.49 \mathrm{C}$ \\
Epicoccum nigrum & 2 & $2 \times 10^{4}$ & $25.13 \mathrm{C}$ & $14.47 \mathrm{C}$ & $35.73 \mathrm{~B}$ \\
Bacillus macerans & 3 & $1 \times 10^{9}$ & $89.92 \mathrm{~A}$ & $73.45 \mathrm{AB}$ & $20.27 \mathrm{C}$ \\
Aspergillus niger & 4 & $2 \times 10^{6}$ & $67.47 \mathrm{~B}$ & $57.87 \mathrm{~B}$ & $32.94 \mathrm{~B}$ \\
Penicillium citrinum & 5 & $2 \times 10^{6}$ & $73.66 \mathrm{~B}$ & $100.00 \mathrm{~A}$ & $33.32 \mathrm{~B}$ \\
Pestalotiopsis sp. & 6 & $2 \times 10^{4}$ & $31.18 \mathrm{C}$ & $-51.19 \mathrm{D}$ & $32.42 \mathrm{~B}$ \\
Cladosporium sp. & 7 & $2 \times 10^{6}$ & $23.92 \mathrm{C}$ & $17.49 \mathrm{C}$ & $23.96 \mathrm{C}$ \\
Phoma sp. & 8 & $2 \times 10^{6}$ & $73.39 \mathrm{~B}$ & $76.47 \mathrm{AB}$ & $33.55 \mathrm{~B}$ \\
C. kahawae & & $2 \times 10^{6}$ & $74.4^{*}$ & $62.9 *$ & $60.12 \mathrm{~A}$ \\
\hline
\end{tabular}

*Figures for C. kahawae taken as the reference point.

- Figures followed by the same letters within columns are not significantly different at $P=0.05$

Table 2 : Effects of mixtures of four coffee berry surface microflora on infection of detached green coffee berries in the laboratory fourteen days after inoculation with $C$. kahawae

Effet des mélanges de quatre microorganismes de surface sur l'infection des baies vertes détachées au laboratoire, quatorze jours après l'inoculation de C. kahawae

\begin{tabular}{cc}
\hline Antagonists Mixtures* & Arc sine (\% infection) \\
\hline $1+2$ & $44.59 \mathrm{BC}$ \\
$1+4$ & $35.04 \mathrm{BCDE}$ \\
$1+7$ & $43.68 \mathrm{BC}$ \\
$1+2+4$ & $27.18 \mathrm{E}$ \\
$1+2+7$ & $32.74 \mathrm{CDE}$ \\
$1+4+7$ & $32.25 \mathrm{CDE}$ \\
$1+2+4+7$ & $42.38 \mathrm{BCD}$ \\
$2+4$ & $29.71 \mathrm{DE}$ \\
$2+4+7$ & $43.88 \mathrm{BC}$ \\
$2+7$ & $43.06 \mathrm{BC}$ \\
$4+7$ & $47.68 \mathrm{~B}$ \\
C. kahawae & $65.18 \mathrm{~A}$ \\
Sterile Distilled Water & $0.57 \mathrm{~F}$ \\
\hline
\end{tabular}

*Antagonists code and individual concentrations as in Table 1.

Figures followed by the same letter are not significantly different at $\mathrm{P}=0.05$ 
Table 3 : Effects of four microflora on the sporulation of Colletotrichum sp. on maturing coffee twigs and their effect when grown on whole maize meal broth on infection of detached green coffee berries by C. kahawae

Effet de quatre micro-organismes sur la sporulation de Colletotrichum sp., sur les jeunes ameaux de caféier et leur effet sur l'infection des baies vertes détachées.

\begin{tabular}{lcc}
\hline Antagonists code* $^{*}$ & $\begin{array}{c}\text { Sporulation index } \\
(\mathrm{SI})\end{array}$ & $\begin{array}{c}\text { \% infection of } \\
\text { detached berries }\end{array}$ \\
\hline 1 & $2.76 \mathrm{BC}$ & $86.67 \mathrm{BC}$ \\
2 & $2.11 \mathrm{C}$ & $90.67 \mathrm{AB}$ \\
4 & $2.96 \mathrm{~B}$ & $84.00 \mathrm{BC}$ \\
7 & $2.98 \mathrm{~B}$ & $82.67 \mathrm{C}$ \\
Sterile distilled water & $4.61 \mathrm{~A}$ & $0.00 \mathrm{E}$ \\
Copper Nordox $(0.4 \%)$ & $2.54 \mathrm{BC}$ & \\
$1+2+4+7$ & --- & $33.33 \mathrm{D}$ \\
C. kahawae & --- & $97.33 \mathrm{~A}$ \\
\hline
\end{tabular}

*Antagonist code as in Table 1

Figures followed by the same letter within columns are not significantly different $(P=0.05)$

\section{DISCUSSION}

The results of this study support a previous theory that the saprophytic microflora on coffee contribute to the low levels of CBD in unsprayed farms and that their removal by fungicides originally applied to control coffee leaf rust may have contributed to increase in CBD (Furtado, 1970 ; Griffiths, 1972, 1981). The work by Masaba (1991) provided evidence for antagonism to $C$. kahawae by saprophytic coffee surface microflora. In this study, the same objective was adopted using different microflora and testing on coffee berries. Six isolates were selected for their antibiosis, inhibiting mycelial growth of $C$. kahawae while two were selected due to their abundance on coffee berries on the assumption of high potential as competitors.

The ability of the microflora to reduce germination and appresoria formation on detached green coffee berries was demonstrated. The observed stimulation of appresoria formation by Pestalotiopsis contrasts the findings of Masaba (1991) but this might have been due to species or isolate differences or differences in the test conditions especially nutrition. Nutrient competition might increase appresoria formation by Colletotrichum sp. The isolates also reduced infection of detached green coffee berries and sporulation by Colletotrichum $s p$. on maturing bark of coffee twigs. These findings imply that the microflora have a wide scope of mechanisms of antagonism to the CBD pathogen. Masaba (1991) also demonstrated inhibition of germination, mycelial growth and infection of detached green coffee berries by the pathogen in presence of many filamentous fungi. Various Bacillus sp. have been shown to be antagonistic to many fungi by antibiosis (Van Driesche, 1996). Pedro (1996) also demonstrated antagonism of $B$. subtilis to $C$. kahawae under laboratory conditions.

Mixtures of the antagonists were also effective against the pathogen and the most striking result was in antisporulation test where use of a mixture of the antagonists greatly enhanced their performance. Such an observation was also made by Raupach and Kloepper (1998) where use of a mixture of Bacillus pumilus, $B$. subtilis and Curtobacterium flaccumfaciens, enhanced the control of Colletotrichum orbiculare, Pseudomonas syringae pv. lachrymans and Erwinia tracheiphila on cucumber. Negative effects may also occur if the bio-control agents are incompatible or environmental conditions change. However, use of mixtures might also improve adaptation to environmental changes and broaden the range of pathogens controlled.

On objective of applied agricultural research is to provide the farmer with technology that can be operated on the farm hence more farm-based rather than factory-based. The test of multiplying the antagonists on whole maize meal broth targeted this objective. The apparatus and procedures used were also farmer friendly. The final preparation was therefore not strictly aseptic but the contaminants were limited compared to the antagonists and this was ascertained by plating the broth at the end of incubation.

Good performance of antagonists in the laboratory may fail in the field due to both biotic and abiotic factors. Testing the antagonism on 
coffee berries aimed at reducing variations that could be due to chemical environment on the plant surface. Multiple microbial interactions might also affect the performance but the development of microbial ecosystem is rather slow on fruit surfaces (Jeffries and Koomen, 1992). The total microflora is also lower on coffee berries than stems (Masaba, 1991). It is therefore suggestive that antagonists to $C$. kahawae might require augmentation by seasonal and well timed applications. The scope of search for $C$. kahawae antagonists among saprophytic coffee surface microflora is large as indicated by this study and that of Masaba, (1991). Yeasts have not been screened for antagonism to $C$. kahawae and they may be more adapted to survive on fruit surfaces (Jeffries and Koomen, 1992) and the dry period. These are areas that require investigations in future.

The results of this paper indicate the possibility of developing a biological control strategy against CBD. The strategy developed will have to compete with the already established control methods. However, the evaluation has to be in consideration of multiple parameters and not singular factors like cost and scope of application (Blakeman and Fokkema, 1982 ; Jeffries and Koomen, 1992). The method may also be adopted for integration into the established procedures. Future research areas thus include field trials, study of mechanisms of action, application procedures, effects of carrier materials on the disease, ecological adaptability, acceptability, non-target effects of the antagonists and screening of more antagonists. Understanding the mechanisms of action may also open up opportunities for development of new groups of agrochemicals (Arie et al., 1998).

\section{CONCLUSION}

This study, though preliminary, has shown wide variety of microflora occurring on coffee surfaces can be harnessed for their potential for antagonizing $C$. kahawae the causal agent of Coffee Berry disease. However there is need to address potential non-target negative effect such as pathogenicity to coffee or other plants and mycotoxin production.

\section{ACKNOWLEDGEMENTS}

I thank Mr. M. M. Miheso, Mr. S. M. Nyoro, Ms J. W. Thuku and Ms C. W. Ngugi (Coffee Research Foundation, Plant Pathology Section) for technical assistance. This paper is published with the permission of the Director of Research, Coffee Research Foundation, Ruiru, Kenya.

\section{REFERENCES}

Arie (T.), (Y.) Kibayashi, (G.) Okada, (Y.) Kono, and (I.) Yamagushi. 1998. Control of soil borne clubroot disease of cruciferous plants by epoxydon from Phoma glomerata. PI. Path. $47: 743-748$

Blakeman (J. P) and (N. J.) Fokkema.1982. Potential for biological control of plant diseases on phylloplane. Ann. Rev. Phytopath. $20: 167$ - 192

Duris (D), 2002. Coffee and Ochratoxin contamination in (E.) Hanak, (E.) Boutrif, (P.) Fabre and (M.) Pineiro (Ed.) proceedings of the international workshop, CIRAD-FAO 11-13 December 2000, Montpellier, France, pp 67-69

Furtado (I), 1969. Effect of copper fungicides on the occurrence of the pathogenic strains of Colletotrichum coffeanum. Trans. Brit. Myco. Soc. $53: 325-328$

Furtado (I), 1970. The effect of copper fungicides upon the bark microflora on Coffea arabica with particular reference to the pathogenic strains of Colletotrichum coffeanum. PhD Thesis, University of East Africa.

Gibbs (J. N.), 1972. Effects of fungicides on the population of Colletotrichum and other fungi in the bark of coffee. Ann. Appl. Biol. $70: 35-47$.

Griffiths (E.), 1972. «Negative» effects of fungicides in coffee. Trop. Sci. $14: 79$ - 89.

Griffiths (E), 1981. latrogenic plant diseases. Ann. Rev. Phytopath. $19: 69$ - 83.

Griffiths (E.), (J. N.) Gibbs, and (J. M.) Waller. 1971. Control of coffee berry disease. Ann.Appl. Biol. $67: 45$ - 74.

Jeffries (P.) and (I.) Koomen. 1992. Strategies and prospectives for biological control of 
diseases caused by Colletotrichum. In (J. A.) Bailey and (M. J.) Jeger Ed.). Colletotrichum : Biology, pathology and control. C.A.B. International, Wallingford, 337 - 357.

Masaba (D. M.), 1986. Procedures for testing new fungicides for the control of coffee berry and leaf rust diseases in Kenya. Kenya Coffee $51: 343$ - 349.

Masaba (D. M.), 1987. Efficacy of reduced rates of copper formulations against coffee leaf rust in Kenya. Kenya Coffee 52 : 65 - 71.

Masaba (D. M.), 1991. The role of saprophytic surface microflora in the development of coffee berry disease (Colletotrichum coffeanum) in Kenya. PhD Thesis, Reading University, 241p

Masaba (D. M.) and (J. M.) Waller. 1992. Coffee berry disease : The current status. In (J.A) Bailey and (M. J.) Jeger Ed.). Colletotrichum: Biology, pathology and control. C.A.B. International, Wallingford, 237 - 249

McDonald (J.), 1926. A preliminary account of a disease of green coffee berries in Kenya. Trans. Brit. Mycol. Soc 2 : 145 - 154.
Mulinge (S. K.) and (E.) Griffiths. 1974. Effects of fungicides on leaf rust, berry disease, foliation and yield of coffee. Trans. Brit. Mycol. Soc. 62 : 495 - 507

Pedro (J. N. M.), 1996. Controlo biologico da anthracnose dos frutos do Coffea arabica pelo Bacillus subtilis em condicoes de laboratorio. Instituto Nacional de Investigacao Agraria, Estacao. Agronomica National, Oeiras, Portugal, 39p.

Raupach (G. S) and (J. N.) Kloepper. 1998. Mixtures of plant growth promoting Rhizobacteria enhance biological control of multiple cucumber pathogens. Phytopath. 88 : 158 - 164.

RAYNER (R. W.), 1957. Tonic copper spraying of coffee. Proc. Nairobi Sci. and Philo. Soc. 9 : $12-16$.

Van Driesche (R. G) and (J.S.) Bellow Jr. 1996. Biological control. Chapman and Hall, New York, $539 \mathrm{p}$.

Van Der Vossen (H. A. M.), 1982. Consequences of phytotonic effects of fungicides to breeding for disease resistance, yield and quality in Coffea arabica. J. Hort. Sci. $57: 321-329$. 